\title{
Proportion and factors of death among preterm neonates admitted in University of Gondar comprehensive specialized hospital neonatal intensive care unit, Northwest Ethiopia
}

\author{
Ayenew Engida Yismaw ${ }^{1 *}$ and Abebe Ayinalem Tarekegn ${ }^{2}$
}

\begin{abstract}
Objective: Neonatal mortality accounts for $43 \%$ of under-five child mortality in Ethiopia where preterm is the second leading cause of neonatal death and steadily increased in low-income countries. Therefore, assessing the proportion of death and associated factors among preterm neonates has a paramount importance in designing an effective strategy to intervene and achieve sustainable development goal.

Results: In this study proportion of preterm neonatal death in this study was $28.8 \%$ [95\% Cl $(25.1,32.9)]$. Complications during index pregnancy $[\mathrm{AOR}=1.92,95 \% \mathrm{Cl}(1.09,3.38)]$, gestational age $[\mathrm{AOR}=0.78,95 \% \mathrm{Cl}(0.69,0.91)]$, small for gestational age $[A O R=2.42,95 \% \mathrm{Cl}(1.33,4.38)]$, APGAR score at birth $<7[\mathrm{AOR}=2.39,95 \% \mathrm{Cl}(1.34,4.27)]$, hyaline membrane disease $[A O R=5.15,95 \% \mathrm{Cl}(2.83,9.36)]$, neonatal respiratory distress at admission $[A O R=1.93,95 \%$ $\mathrm{Cl}(1.13,3.31)]$, presence of jaundice $[\mathrm{AOR}=(3.39,95 \% \mathrm{Cl}(1.90,6.05)]$, received kangaroo mother care $[\mathrm{AOR}=0.13$, $95 \% \mathrm{Cl}(0.05,0.35)]$, and hypoglycemia at admission $[\mathrm{AOR}=3.86,95 \% \mathrm{Cl}(2.12,7.06)]$ were statistically significant. The proportion of preterm neonatal death was high. Ministry of health and responsible organizations should give special attention for preterm neonates to prevent life-threatening complications.
\end{abstract}

Keywords: Ethiopia, Preterm, Neonate, Death, Neonatal, Intensive care unit

\section{Introduction}

In the globe, approximately 3.1 million and 2.9 million neonatal deaths were reported in 2010 and 2014, respectively, which accountings $40 \%$ of the under 5 mortality. Despite a steady decline of neonatal mortality in African countries, it is not satisfactory $[1,2]$. Globally, 3 in 4 neonatal deaths were caused by preterm birth complications which accounts for $35 \%$ of all neonatal deaths [3]. Infection (36\%), preterm birth (28\%) and birth asphyxia (23\%) are the most common causes of neonatal mortality in the world [4-6].

Preterm (PT), a birth before 37 completed weeks of gestation, is the most frequent cause of neonatal death

\footnotetext{
*Correspondence: ayenewe07@gmail.com

1 School of Midwifery, College of Medicine and Health Science, University of Gondar, Gondar, Ethiopia

Full list of author information is available at the end of the article
}

and the second leading cause of both neonatal and underfive mortality with multiple short and long-term health threats worldwide [7]. Lack of immunologic competence increases the risk of preterm infants for multiple infectious processes which may lead to long-term neurodevelopmental disorders and chronic lung disease [8].

Ethiopian Demographic and Health Surveys reported that neonatal death was increased from 32\% in 2005 to 43\% in the 2016 and according to United Nations Children's Fund (UNICEF) report, preterm birth which accounts $23 \%$ was believed to be a major and direct cause of neonatal death in Ethiopia $[9,10]$. Causal factors linked to preterm birth are medical conditions of the mother or fetus, genetic influences, environmental exposure, infertility treatments, behavioral and socio-economic factors, medically indicated preterm delivery as well as iatrogenic prematurity $[11,12]$. 
Studies reported that preterm neonatal mortality ranged from 15 to $36 \%[1,13,14]$. Reports from the worlds' Low to Middle-income countries showed that 34 to $40 \%$ of neonatal mortality were contributed by preterm [5, 15-17]. Hospital-based studies in Africa reported that preterm neonatal mortality accounted for about 15.7 to $29.6 \%$ [18, 19]. Studies in Ethiopia reported that preterm neonatal mortality rate ranges from $18 \%$ up to more than $40 \%$ [20-26].

Different studies conducted so far showed that rural residency [18, 24], maternal age [27, 28], place of birth $[20,29]$. Obstetric risk factors were not having ANC [15-17], being prim para [4, 24], having any pregnancy complications $[20,29]$, Labour and delivery complications $[15,19,23]$, having previous bad obstetric history $[16,23]$ were risk factors for preterm neonatal death.

Neonatal related risk factors include being male sex [15-17, 30], low birth weight at birth [15, 24], gestational age (GA) at birth and neonatal congenital malformations [18, 23], neonatal clinical problems like respiratory distress syndrome (RDS), perinatal asphyxia (PNA), hyaline membrane disease (HMD), jaundice, hypoglycemia, hypothermia and neonatal sepsis $[6,23,26,31]$, timely initiation of breastfeeding upon birth and kangaroo mother care (KMC) were reported as factors of preterm neonatal death $[26,28]$.

Even if premature birth is not an acute disease, it is one of the major causes of infants' death and preterm birth continues to be significant public health problem by increasing the average cost of medical care for a premature and low birth-weight baby for the first year of life for developing country like Ethiopia. These high medical expenses could burden both the parents, families as well as the community. Therefore, this is the dual agenda to prevent preterm birth and reduce neonatal death which requires a comprehensive research strategy to end the preventable deaths of newborns and under-five children.

\section{Main text \\ Methodology \\ Study design and setting}

Retrospective cross-sectional study was conducted to assess the proportion of death and its associated factors among preterm neonates admitted in NICU from January 2016 to March 2018 in University of Gondar comprehensive specialized hospital neonatal intensive care unit. The hospital is one of the largest teaching hospital found in Amhara region providing tertiary level care for more than seven million people in the North West part of the country.

\section{Sample size and sampling procedure}

All preterm neonates admitted to neonatal intensive care unit at the University of Gondar comprehensive specialized hospital. Thus, preterm neonates admitted to NICU with a gestational age of less than 37 completed weeks were source population and all preterm neonates who were admitted to neonatal intensive care unit (NICU) at University of Gondar comprehensive specialized hospital from January 2016 to March 2018 were the study population. A total of 516 preterm neonates admitted in NICU were included in the study.

\section{Data collection method and instruments}

Medical records were reviewed and preterm neonatal cards were identified by their medical registration/card number. Then data were extracted using structured and pretested data extraction checklist prepared in English from HMIS registration format and patients' card. Trained midwife professionals had collected the data.

\section{Data quality assurance and analysis}

Data were entered into EPI info version 7 and imported to Stata version 14 statistical software for further analysis. Descriptive statistical data analysis was done and followed by bivariate and multivariable analysis in order to see the statistical association between the outcome and explanatory variables. Variables which showed significant association in the bivariate analysis were entered into multivariable logistic regression. The degree of association was assessed using odds ratio with $95 \%$ confidence interval and $\mathrm{P}$-value $<0.05$ were taken as statically significant.

\section{Results}

Socio-demographic and obstetric characteristics of mothers In this study, 516 preterm neonates' data were included in the analysis. Two-third (66.86\%) of the mothers were resided out of Gondar town. About onefifth 417 (80.81\%) of mothers were in the age range of $20-34$ years with mean age of 26.52 years (Table 1 ).

\section{Characteristics of the preterm neonates}

Among 516 preterm neonates, 303 (58.73\%) were males and 109 (21.12\%) were small for gestational age. About one-sixth $82(15.89 \%)$ had a body temperature of greater or equal to $36{ }^{\circ} \mathrm{C}$ measured within $1 \mathrm{~h}$ of admission and $371(71.9 \%)$ were heated under radiant warmer. (Table 2).

\section{Proportion of preterm neonatal death}

This finding showed that 149 (28.8\%) with 95\% CI; $(25.1,32.9)$ neonates died. From this $17(11.4 \%)$ of them 
Table 1 Socio-demographic and obstetric characteristics of mothers of preterm neonates admitted in NICU at University of Gondar comprehensive specialized Hospital from January 2016 to March $2018(n=516)$

\begin{tabular}{|c|c|c|}
\hline Characteristics & Frequency & Percent \\
\hline \multicolumn{3}{|l|}{ Maternal residence } \\
\hline Gondar town & 171 & 33.14 \\
\hline Out of Gondar town & 345 & 66.86 \\
\hline \multicolumn{3}{|l|}{ Age of women in years } \\
\hline$<20$ & 41 & 7.95 \\
\hline $20-34$ & 417 & 80.81 \\
\hline$\geq 35$ & 58 & 11.24 \\
\hline \multicolumn{3}{|l|}{ Had ANC in index pregnancy } \\
\hline Yes & 486 & 94.2 \\
\hline No & 30 & 5.8 \\
\hline \multicolumn{3}{|l|}{ Parity (Number of births) } \\
\hline I & 230 & 44.57 \\
\hline$\|-I V$ & 196 & 37.99 \\
\hline$\geq V$ & 90 & 17.44 \\
\hline \multicolumn{3}{|c|}{ Complication during index pregnancy } \\
\hline Yes & 120 & 23.26 \\
\hline No & 396 & 76.74 \\
\hline \multicolumn{3}{|l|}{ Previous bad obstetrics history } \\
\hline Yes & 80 & 15.5 \\
\hline No & 436 & 84.5 \\
\hline \multicolumn{3}{|l|}{ Type of pregnancy } \\
\hline Singleton & 331 & 64.15 \\
\hline Multiple & 185 & 35.85 \\
\hline \multicolumn{3}{|l|}{ Onset of labor } \\
\hline Elective caesarean section & 56 & 10.85 \\
\hline Spontaneous & 425 & 82.37 \\
\hline Induced & 35 & 6.78 \\
\hline \multicolumn{3}{|l|}{ Place of birth } \\
\hline Home & 23 & 4.50 \\
\hline Health center & 120 & 23.25 \\
\hline Hospital & 373 & 72.25 \\
\hline \multicolumn{3}{|l|}{ Mode of delivery } \\
\hline Spontaneous vaginal delivery & 384 & 74.42 \\
\hline Caesarean section & 117 & 22.67 \\
\hline Instrument assisted delivery & 15 & 2.91 \\
\hline \multicolumn{3}{|c|}{ Duration of labour in hours $(n=460)$} \\
\hline$<4$ & 52 & 11.30 \\
\hline $4-18$ & 354 & 77.00 \\
\hline$>18$ & 54 & 11.70 \\
\hline
\end{tabular}

were died within the first 24 h of life and 127 (85.23\%) died in the first 7 days of life (early neonatal death). The causes of death were multifactorial, not single. However, the leading causes were PNA (31\%), HMD (26\%), and cardiorespiratory arrest due to apnea (17\%).

\section{Associated factors of proportions of death for preterm neonates}

Univariate and multivariable logistic regression was used to identify associated factors of death for preterm neonates admitted in the NICU.

Findings from bivariate analysis showed that complications during index pregnancy, previous bad obstetric history, neonatal respiratory distress, gestational age, small for gestational age, low APGAR score at birth, HMD, PNA, jaundice, receiving KMC, hypoglycemia, hypothermia, and temperature within $1 \mathrm{~h}$ of admission in ${ }^{\circ} \mathrm{C}$ were significantly associated with death of preterm neonates.

However, in the multi-variable analysis complications during the index pregnancy, neonatal respiratory distress, gestational age, small for gestational age, low APGAR score at birth, HMD, jaundice, receiving KMC, and hypoglycemia remained statistically significant factors.

The odds of death among preterm neonates delivered from mothers having complication during index pregnancy was 1.92 times higher as compared to their counterparts $[\mathrm{AOR}=1.92 ; 95 \% \mathrm{CI}(1.09,3.38)]$.

The odds of death for preterm neonates who had $<$ APGAR score at birth was 2.4 times higher than those who had $>$ APGAR score at birth $[\mathrm{AOR}=2.39$; $95 \%$ CI $(1.34,4.27)]$.

Providing KMC for all preterm neonates reduce the odds of death by $87 \%$ as compared to not provided KMC $[\mathrm{AOR}=0.13 ; 95 \% \mathrm{CI}(0.05,0.35)]$ (Table 3$)$.

\section{Discussion}

The proportion of death among preterm neonates admitted in University of Gondar Comprehensive Specialized Hospital NICU was 28.8\% [95\% CI (25.1, 32.9)]. The causes of death weren't single problem rather combination of problems lead to death and the major once were PNA, HMD, jaundice, clinical sepsis and cardiorespiratory arrest due to apnea. All the causes are preventable by improving timely health seeking behavior of the community, upgrading the quality of care provided in the hospitals and health centers to be safe, clean and well equipped with all the infrastructures. This finding is in line with studies conducted in a multi-country level analysis reported by WHO and UNICEF 29.3\% [14] and in Kenya 29.6\% [19]. However, this finding was higher than studies conducted in a multi-country analysis by the lead of saving the children 15\% [13] Cameroon 15.7\% [18] Jimma Ethiopia 18.2\% [20] and northern rural Ethiopia $23.7 \%$ [21].

This might be due to the difference in the study setting and the study population which was most vulnerable preterm neonates only. 
Table 2 Characteristics of preterm neonates admitted in NICU at University of Gondar comprehensive specialized Hospital from January 2016 to March 2018 $(n=516)$

\begin{tabular}{|c|c|c|}
\hline Characteristics & Frequency & Percent \\
\hline \multicolumn{3}{|c|}{ Sex of the neonate } \\
\hline Male & 303 & 58.73 \\
\hline Female & 213 & 41.27 \\
\hline \multicolumn{3}{|c|}{ Gestational age (weeks) } \\
\hline$<32$ & 107 & 20.74 \\
\hline $32-35$ & 269 & 52.13 \\
\hline $35-37$ & 140 & 27.13 \\
\hline \multicolumn{3}{|c|}{ Weight for gestational age at birth } \\
\hline Small & 109 & 21.12 \\
\hline Appropriate & 407 & 78.88 \\
\hline \multicolumn{3}{|c|}{ Newborn cry immediately at birth } \\
\hline Yes & 385 & 74.61 \\
\hline No & 131 & 25.39 \\
\hline \multicolumn{3}{|c|}{ Bag and mask resuscitation at birth } \\
\hline Yes & 209 & 40.5 \\
\hline No & 307 & 59.5 \\
\hline \multicolumn{3}{|c|}{ Newborns temperature with in $1 \mathrm{~h}$ of admission } \\
\hline$\leq 32$ & 15 & 2.91 \\
\hline $32.1-34$ & 151 & 29.26 \\
\hline $34.1-35$ & 158 & 30.62 \\
\hline $35.1-36$ & 110 & 21.32 \\
\hline$\geq 36$ & 82 & 15.89 \\
\hline \multicolumn{3}{|c|}{ Peri-natal asphyxia diagnosed at birth } \\
\hline Yes & 137 & 26.55 \\
\hline No & 379 & 73.45 \\
\hline \multicolumn{3}{|c|}{ Newborn diagnosed with respiratory distress } \\
\hline Yes & 142 & 27.52 \\
\hline No & 374 & 72.48 \\
\hline \multicolumn{3}{|c|}{ Hypothermia diagnosed at admission } \\
\hline Yes & 426 & 82.56 \\
\hline No & 90 & 17.44 \\
\hline \multicolumn{3}{|c|}{ Hypoglycemia diagnosed at admission } \\
\hline Yes & 112 & 21.71 \\
\hline No & 404 & 78.29 \\
\hline \multicolumn{3}{|l|}{ Jaundice } \\
\hline Yes & 127 & 24.61 \\
\hline No & 389 & 75.39 \\
\hline \multicolumn{3}{|c|}{ Newborn diagnosed with clinical sepsis } \\
\hline Yes & 401 & 77.71 \\
\hline No & 115 & 22.29 \\
\hline \multicolumn{3}{|c|}{ Neonate received photo therapy } \\
\hline Yes & 143 & 27.71 \\
\hline No & 373 & 72.29 \\
\hline \multicolumn{3}{|c|}{ Neonate received continuous positive airway pressure } \\
\hline Yes & 287 & 55.62 \\
\hline No & 229 & 44.38 \\
\hline
\end{tabular}

Table 2 (continued)

\begin{tabular}{lcc}
\hline Characteristics & Frequency & Percent \\
\hline Newborn received kangaroo mother care & & \\
Yes & 68 & 13.18 \\
No & 448 & 86.82 \\
Newborn heated with radiant warmer & & \\
Yes & 371 & 71.90 \\
No & 145 & 28.10 \\
\hline
\end{tabular}

In contrast, this finding was lower than studies conducted in population-based study from low to middleincome countries 37.5\% [15], Urban Pakistan 34\% [5], Jordan 40\% [16], Johannesburg South Africa 64\% [17], Tigray region Northern Ethiopia 34\% [22-24] and Jimma University Specialized Hospital, Ethiopia 34.9\% [26].

This might be due to the time variation where neonatal mortality is decreasing, access of health care service was increased, the health seeking and utilization behavior of the community and accessibility of trained health care providers are comparatively increased.

This finding showed that a neonate delivered from mothers with Complication during index pregnancy increased the odds of death by $92 \%$ as compared with their counterpart $[\mathrm{AOR}=1.92,95 \% \mathrm{CI}(1.09,3.38)]$. This finding was supported by findings in northern Ethiopia [24], Ethiopian, DHS data [28], the sub-urban hospitals of Cameroon [18] and Johannesburg Central Hospital [29]. This similarity might be due to the complications (PROM, PIH, and delivery complications) affecting the pregnancy to result in preterm labour and acquired infections leading to neonatal death.

In this study, as the gestational age increase in a week, the odds of death was decreased by $22 \%$ [AOR of 0.78 ; $95 \%$ CI $(0.69,0.91)]$. This finding was in line with findings in Jimma University specialized hospital [26] and Addis Ababa St. Paul's Hospital Millennium Medical College [25]. This was because, as gestational age increases fetal maturity will be maximized and risk of life-threatening complications associated with prematurity may decrease.

This study showed that a neonate with small for gestational age at birth was 2.42 times at higher risk of death compared to appropriate for gestational age $[\mathrm{AOR}=2.42$, $95 \%$ CI $(1.33,4.38)]$. This was supported by a study conducted in Jimma Zone [20] Ethiopian, DHS data [27], and Johannesburg Central Hospital [29]. The possible reasons might be due to that if small for gestational age the occurrence of life-threatening complications which lead to death is high compared to appropriate for gestational age neonates.

The odds of death was increased by 2.4 times for a neonate with APGAR score $<7$ at birth as compared to the 
Table 3 Factors associated with proportion of death among preterm neonates admitted in NICU at University of Gondar specialized referral Hospital from January 2016 to March 2018 ( $n=516)$

\begin{tabular}{|c|c|c|}
\hline Predictor variables & COR $(95 \% \mathrm{Cl})$ & AOR $(95 \% \mathrm{Cl})$ \\
\hline \multicolumn{3}{|l|}{ Residence of the mother } \\
\hline Gondar Town & 1 & 1 \\
\hline Out of Gondar Town & $1.66(1.08,2.54)$ & $1.17(0.67,2.01)$ \\
\hline \multicolumn{3}{|c|}{ Complication during index pregnancy } \\
\hline No & 1 & 1 \\
\hline Yes & $1.95(1.27,2.99)$ & $1.92(1.09,3.38)^{*}$ \\
\hline \multicolumn{3}{|l|}{ Previous bad obstetrics history } \\
\hline No & 1 & 1 \\
\hline Yes & $1.82(1.11,2.98)$ & $1.86(0.95,3.63)$ \\
\hline Gestational age & $0.64(0.57,0.71)$ & $0.78(0.69,0.91)^{* *}$ \\
\hline \multicolumn{3}{|l|}{ Weight for gestational age at birth } \\
\hline Small & $2.05(1.32,3.18)$ & $2.42(1.33,4.38)^{*}$ \\
\hline Appropriate & 1 & 1 \\
\hline \multicolumn{3}{|l|}{ APGAR score at birth } \\
\hline$\geq 7$ & 1 & 1 \\
\hline$<7$ & $3.53(2.32,5.37)$ & $2.39(1.34,4.27)^{*}$ \\
\hline \multicolumn{3}{|l|}{ Neonates diagnosed for HMD } \\
\hline No & 1 & 1 \\
\hline Yes & $8.04(4.98,12.98)$ & $5.15(2.83,9.36)^{* *}$ \\
\hline \multicolumn{3}{|l|}{ Neonatal hypothermia at admission } \\
\hline No & 1 & 1 \\
\hline Yes & $2.10(1.18,3.74)$ & $1.06(0.46,2.47)$ \\
\hline \multicolumn{3}{|c|}{ Neonatal respiratory distress at admission } \\
\hline No & 1 & 1 \\
\hline Yes & $2.56(1.70,3.85)$ & $1.93(1.13,3.31)^{*}$ \\
\hline \multicolumn{3}{|l|}{ Clinically diagnosed PNA } \\
\hline No & 1 & 1 \\
\hline Yes & $2.65(1.76,4.01)$ & $1.38(0.77,2.47)$ \\
\hline \multicolumn{3}{|l|}{ Neonate diagnosed with jaundice } \\
\hline No & 1 & 1 \\
\hline Yes & $1.82(1.19,2.77)$ & $3.39(1.90,6.05)^{* *}$ \\
\hline \multicolumn{3}{|l|}{ Neonate received KMC } \\
\hline No & 1 & 1 \\
\hline Yes & $0.25(0.11,0.55)$ & $0.13(0.05,0.35)^{* *}$ \\
\hline \multicolumn{3}{|c|}{ Neonate diagnosed with hypoglycemia } \\
\hline No & 1 & 1 \\
\hline Yes & $2.48(1.61,3.84)$ & $3.86(2.12,7.06)^{*}$ \\
\hline $\begin{array}{l}\text { Neonatal temperature measured } \\
\text { within } 1 \mathrm{~h} \text { of admission in }{ }^{\circ} \mathrm{C}\end{array}$ & $0.69(0.59,0.80)$ & $0.83(0.67,1.02)$ \\
\hline
\end{tabular}

* P-value $<0.05,{ }^{* *}$ P-value $<0.001$

counterpart with $[\mathrm{AOR}=2.39,95 \% \mathrm{CI}(1.34,4.27)]$. This result was comparable with the findings in Addis Ababa St Paul's Hospital Millennium Medical College [25], suburban hospitals of Cameroon [18], and Taubaté University Hos-pital, Brazil [31].
In the current study, the odds of preterm neonatal death among cases of HMD was 5 times higher compared to none cases $[\mathrm{AOR}=5.15,95 \% \mathrm{CI}(2.83,9.36)]$. This finding was comparable with findings in Jimma University specialized hospital [26] and Johannesburg Central Hospital [29]. This might be HMD is a disease of prematurity affecting respiratory function leading to death in preterm neonates.

The odds of death for preterm neonates with respiratory distress was 1.9 times higher than their counterparts $[\mathrm{AOR}=1.93,95 \%$ CI $(1.13,3.31)]$. This finding was in line with findings of Butajira District, South Central Ethiopia [6], and Jimma University specialized hospital [26]. Because it is life-threatening complication leading to hypoxic-ischemic encephalopathy.

Preterm neonates with jaundice had 3.4 times higher odds of death than their counterparts [AOR $=3.39,95 \%$ CI $(1.90,6.05)]$. This finding was in line with findings in Jimma University specialized hospital [26]. This might be due to that gastrointestinal immaturity, liver enzyme deficiency leading to excess production of bilirubin to result in brain toxicity and death.

Hypoglycemia was significantly associated with the odds of death for preterm neonates, $[\mathrm{AOR}=3.86,95 \% \mathrm{CI}$ $(2.12,7.06)]$. This might be because of luck of adipose fat tissue serving as a source of glucose to adapt the extrauterine life until they maintain through feeding.

This finding showed that the odds of death among preterm neonates received KMC was lowered by $87 \%$ $[\mathrm{AHR}=0.13,95 \%$ CI $(0.05,0.35)]$. This might be KMC prevents hypothermia by reducing body surface area to the external environment and helps easily accessing breastfeed on demand.

\section{Conclusions}

In this study the proportion of preterm neonatal death was high. Complications during the index pregnancy, respiratory distress, gestational age, small for gestational age, low APGAR score at birth, HMD, jaundice, receiving $\mathrm{KMC}$, and hypoglycemia were found to be significant factors for preterm neonatal death. All responsible bodies should work on quality care at ANC to maximize maternal health conditions, access NICU with infrastructures and skilled manpower at health institutions and give special care for preterm to avoid complications due to preterm.

\section{Limitation}

It was a cross-sectional study and may not show the cause and effect relationship. A secondary source of data may lack some important variables affecting the outcome variables. 


\begin{abstract}
Abbreviations
ANC: antenatal care; AOR: adjusted odds ratio; APGAR: Appearance Pulse Grimace Activity Respiration; APH: antepartum hemorrhage; B.Sc:: Bachelors of Science; Cl: confidence interval; COR: crude odd ratio; EDHS: Ethiopian Demographic and Health Survey; GA: gestational age; HIV: human immunedeficiency virus; HMD: hyaline membrane disease; HR: hazard ratio; IRB: Institutional Review Board; KMC: kangaroo mother care; NEC: necrotizing enterocolitis; NCPAP: nasal continuous positive air pressure; NICU: neonatal intensive care unit; NGOs: non-governmental organizations; NMR: neonatal mortality rate; OR: odds ratio; PIH: pregnancy induced hypertension; PNA: perinatal asphyxia; PROM: prelabour rupture of membrane; PT: preterm; RDS: respiratory distress syndrome; UN: United Nations; UNICEF: United Nations International Emergency Children Fund; WHO: World Health Organization.
\end{abstract}

\section{Authors' contributions}

AEY conceived and design the idea, participated in the data collection process, analyze data and wrote the paper. AAT participated in data analysis and wrote the paper. Both authors read and approved the final manuscript.

\section{Author details \\ ${ }^{1}$ School of Midwifery, College of Medicine and Health Science, University of Gondar, Gondar, Ethiopia. ${ }^{2}$ Department of Health Economics, Institute of Public Health, College of Medicine and Health Sciences, University of Gondar, Gondar, Ethiopia.}

\section{Acknowledgements}

We would like to acknowledge the Department of Epidemiology and Biostatistics, Institute of Public Health, College of Medicine and Health Sciences, University of Gondar for their support. We also acknowledge the University of Gondar comprehensive specialized Hospital medical records office staffs for their co-operation to get client charts and registrations.

\section{Competing interests}

The authors declared no potential competing interest with respect to the research, authorship, and publication of this article.

\section{Availability of data and materials}

Data will be available upon responsible request from the corresponding author using "ayenewe07@gmail.com".

\section{Consent for publication}

Not applicable.

\section{Ethics approval and consent to participate}

Ethical approval was obtained from the Institutional Review Board (IRB) of the Institute of Public Health, College of Medicine and Health Science University of Gondar. Permission letter from University Hospital was also secured before data collection. Names of patients were not included during data collection.

\section{Funding}

The authors have also declared that no financial support in the research, authorship, and publication of this article was received.

\section{Publisher's Note}

Springer Nature remains neutral with regard to jurisdictional claims in published maps and institutional affiliations.

Received: 5 October 2018 Accepted: 29 November 2018

Published online: 06 December 2018

\section{References}

1. Lawn JE, Blencowe H, Oza S, You D, Lee AC, Waiswa P, et al. Every newborn: progress, priorities, and potential beyond survival. Lancet. 2014;384(9938):189-205.

2. Rajaratnam JK, Marcus JR, Flaxman AD, Wang H, Levin-Rector A, Dwyer L, et al. Neonatal, postneonatal, childhood, and under-5 mortality for 187 countries, 1970-2010: a systematic analysis of progress towards Millennium Development Goal 4. Lancet. 2010;375(9730):1988-2008.
3. Wardlaw T, You D, Hug L, Amouzou A, Newby H. UNICEF Report: enormous progress in child survival but a greater focus on newborns urgently needed. Reprod Health. 2014;11(1):82

4. Lawn JE, Cousens S, Zupan J. 4 million neonatal deaths: When? Where? Why? Lancet. 2005;365(9462):891-900.

5. Jehan I, Harris H, Salat S, Zeb A, Mobeen N, Pasha O, et al. Neonatal mortality, risk factors and causes: a prospective population-based cohort study in urban Pakistan. Bull World Health Organ. 2009;87(2):130-8.

6. Gizaw M, Molla M, Mekonnen W. Trends and risk factors for neonatal mortality in Butajira District, South Central Ethiopia, (1987-2008): a prospective cohort study. BMC Pregnancy Childbirth. 2014;14(1):64.

7. Howson C, Kinney M, Lawn J. Born too soon: the global action report on preterm birth. Geneva: World Health Organization; 2012. p. 1-126.

8. Villar J, Ismail LC, Victora CG, Ohuma EO, Bertino E, Altman DG, et al. International standards for newborn weight, length, and head circumference by gestational age and sex: the Newborn Cross-Sectional Study of the INTERGROWTH-21st Project. Lancet. 2014;384(9946):857-68.

9. EDHS (2016) Central Statistical Agency. Ethiopian Demographic and Health Survey Addis Ababa. 2016.

10. UNICEF. Maternal, newborn and child survival, country profile. Ethiopia, Statistics and Monitoring Section/Policy and Practice. New York: UNICEF; 2012.

11. Pennell CE, Jacobsson B, Williams SM, Buus RM, Muglia LJ, Dolan SM, et al. Genetic epidemiologic studies of preterm birth: guidelines for research. Am J Obstet Gynecol. 2007;196(2):107-18.

12. Goldenberg RL, Culhane JF, lams JD, Romero R. Epidemiology and causes of preterm birth. Lancet. 2008;371(9606):75-84.

13. Lawn JE, Kinney MV, Black RE, Pitt C, Cousens S, Kerber K, et al. Newborn survival: a multi-country analysis of a decade of change. Health Policy Plan. 2012;27(suppl_3):iii6-28.

14. WHO U. Countdown to 2015: maternal, newborn and child survival. Decade Report (2000-2010): taking stock of maternal, newborn and child survival Geneva: WHO, UNICEF. 2010.

15. Dhaded SM, Somannavar MS, Vernekar SS, Goudar SS, Mwenche M, Derman $\mathrm{R}$, et al. Neonatal mortality and coverage of essential newborn interventions 2010-2013: a prospective, population-based study from low-middle income countries. Reprod Health. 2015;12(2):S6.

16. Razeq NMA, Khader YS, Batieha AM. The incidence, risk factors, and mortality of preterm neonates: a prospective study from Jordan (2012-2013). Turk J Obstet Gynecol. 2017;14(1):28.

17. Ballot DE, Chirwa TF, Cooper PA. Determinants of survival in very low birth weight neonates in a public sector hospital in Johannesburg. BMC Pediatrics. 2010;10(1):30.

18. Ndombo PK, Ekei QM, Tochie JN, Temgoua MN, Angong FTE, Ntock FN, et al. A cohort analysis of neonatal hospital mortality rate and predictors of neonatal mortality in a sub-urban hospital of Cameroon. Ital J Pediatrics. 2017;43(1):52.

19. Mwaniki MK, Gatakaa HW, Mturi FN, Chesaro CR, Chuma JM, Peshu NM, et al. An increase in the burden of neonatal admissions to a rural district hospital in Kenya over 19 years. BMC Public Health. 2010;10(1):591.

20. Debelew GT, Afework MF, Yalew AW. Determinants and causes of neonatal mortality in Jimma zone, southwest Ethiopia: a multilevel analysis of prospective follow up study. PLoS ONE. 2014;9(9):e107184.

21. Weldearegawi B, Melaku YA, Abera SF, Ashebir Y, Haile F, Mulugeta A, et al. Infant mortality and causes of infant deaths in rural Ethiopia: a population-based cohort of 3684 births. BMC Public Health. 2015;15(1):770.

22. Mengesha HG, Sahle BW. Cause of neonatal deaths in Northern Ethiopia: a prospective cohort study. BMC Public Health. 2017;17(1):62.

23. Mengesha HG, Wuneh AD, Lerebo WT, Tekle TH. Survival of neonates and predictors of their mortality in Tigray region, Northern Ethiopia: a prospective cohort study. BMC Pregnancy Childbirth. 2016;16(1):202.

24. Mengesha HG, Lerebo WT, Kidanemariam A, Gebrezgiabher G, Berhane Y. Pre-term and post-term births: predictors and implications on neonatal mortality in Northern Ethiopia. BMC Nurs. 2016;15(1):48.

25. Tekleab AM, Amaru GM, Tefera YA. Reasons for admission and neonatal outcome in the neonatal care unit of a tertiary care hospital in Addis Ababa: a prospective study. Res Rep Neonatol. 2016;6:17-23.

26. Wesenu M, Kulkarni S, Tilahun T. Modeling determinants of time-to-death in premature infants admitted to neonatal intensive care unit in Jimma University Specialized Hospital. Ann Data Sci. 2017;4(3):361-81. 
27. Selemani M, Mwanyangala MA, Mrema S, Shamte A, Kajungu D, Mkopi $A$, et al. The effect of mother's age and other related factors on neonatal survival associated with first and second birth in rural, Tanzania: evidence from Ifakara health and demographic surveillance system in rural Tanzania. BMC Pregnancy Childbirth. 2014;14(1):240.

28. Wakgari N, Wencheko E. Risk factors of neonatal mortality in Ethiopia. Ethiop J Health Dev. 2013;27(3):192-9.

29. Ballot DE, Chirwa T, Ramdin T, Chirwa L, Mare I, Davies VA, et al. Comparison of morbidity and mortality of very low birth weight infants in a
Central Hospital in Johannesburg between 2006/2007 and 2013. BMC Pediatrics. 2015;15(1):20.

30. Cupen K, Barran A, Singh V, Dialsingh I. Risk factors associated with preterm neonatal mortality: a case study using data from Mt. Hope Women's Hospital in Trinidad and Tobago. Children. 2017:4(12):108.

31. Risso SDP, Nascimento LFC. Risk factors for neonatal death in neonatal intensive care unit according to survival analysis. Revista Brasileira de terapia intensiva. 2010;22(1):19-26.
Ready to submit your research? Choose BMC and benefit from:

- fast, convenient online submission

- thorough peer review by experienced researchers in your field

- rapid publication on acceptance

- support for research data, including large and complex data types

- gold Open Access which fosters wider collaboration and increased citations

- maximum visibility for your research: over $100 \mathrm{M}$ website views per year

At BMC, research is always in progress.

Learn more biomedcentral.com/submissions 